\title{
Correction to: Acaricidal and insecticidal responses of Cinnamomum cassia oils and main constituents
}

Min-Seung Kang and Hoi-Seon Lee* (i)

\section{Correction to: Appl Biol Chem (2018) 61(6):653-659 https://doi.org/10.1007/s13765-018-0402-4}

Following the publication of the original article [1], the authors reported that the 'Acknowledgements' section was published with an error.

The 'Acknowledgements' section was published as:

- This research was supported by a grant of the Korea Health Technology R\&D Project through the Korea Health Industry Development Institute (KHIDI), funded by the Ministry of Health and Welfare, Republic of Korea (Grant Number: HG18C0055).

The correct 'Acknowledgements' section should read:

- This research was supported by Republic of Korea (Government-wide R\&D Fund project for infectious disease research, HG18C0055).

The original article can be found online at https://doi.org/10.1007/s1376 5-018-0402-4

\section{Publisher's Note}

Springer Nature remains neutral with regard to jurisdictional claims in published maps and institutional affiliations.

\section{Reference}

1. Kang MS, Lee HS (2018) Acaricidal and insecticidal responses of Cinnamomum cassia oils and main constituents. Appl Biol Chem 61:653-659. https ://doi.org/10.1007/s13765-018-0402-4

*Correspondence: hoiseon@jbnu.ac.kr

Department of Bioenvironmental Chemistry, Chonbuk National

University, Jeonju 54896, Republic of Korea 